\title{
A AURA BENJAMINIANA OU A MORTE DOS VAGALUMES: UM ENSAIO
}

\author{
Cláudio Guilarduci
}

Mauro Rocha Baptista

\begin{abstract}
RESUMO
O presente ensaio é uma reflexão sobre a cena experimental $A$ aura benjaminiana ou a morte dos vagalumes apresentada pelo grupo de pesquisa Ambulatório durante - $1^{\circ}$ Congresso Internacional de Letras, Artes e Cultura (2013), na Universidade Federal de São João del-Rei-UFSJ. Para essa discussão, tomamos por base a ideia de desconstrução da experiência artística para a construção de um compartilhamento do processo vivenciado durante a experimentação cênica. Ao discutir a cena teatral, não é nossa intenção a de transportar o leitor para dentro da cena, mas a de gerar nele o mesmo nível de desconforto e de perda das referências que os participantes da cena puderam vivenciar.
\end{abstract}

Palavras-chave: Experiência. Arte. Walter Benjamin.

\section{THE BENJAMINIAN AURA OR THE DEATH OF FIREFLIES: AN ESSAY}

\begin{abstract}
This paper is a reflection on the experimental scene $A$ aura benjaminiana ou a morte dos vagalumes presented by the research group Ambulatório from UFSJ, during the $1^{\text {st }}$ International Congress on Languages, Arts, and Culture (2013), held by Universidade Federal de São João del-Rei (UFSJ). We based on the idea of deconstruction of the artistic experience so as to build a share of the process lived during the scenic experiment in order to carry out this discussion. As we deconstruct the theatric scene we do not intend to transfer the readers to the scene, however to create on them the same level of discomfort and loss of references which the actors in the scene could experience.
\end{abstract}

Keywords: Experience. Art. Walter Benjamin.

\footnotetext{
Doutor em Teatro pela Universidade Federal do Estado do Rio de Janeiro-UNIRIO. Professor do curso de graduação em Teatro e do Programa de Pós-Graduação em Artes Cênicas-PPGAC da UFSJ. Brasileiro, residente em São João del Rei MG. Email: quilarduci@ufsj.edu.br
}

Doutor em Ciência da Religião pela Universidade Federal de Juiz de Fora. Professor vinculado ao Departamento "Ciências Humanas" da UEMG. Coordenador da pesquisa "Uma política para a formade-vida: Inoperância, messianismo e profanação em Giorgio Agamben" (CNPq). Brasileiro, residente em Barbacena-MG. Email: m-baptista@uol.com.br 
A proposta de se fazer um ensaio sobre uma cena apresentada a público restrito ${ }^{1}$ já é por si só um desafio, ainda mais quando a intenção é a de uma desconstrução do evasivo brilho do vagalume e de tomar esse lapso como paradigma da desconstrução da experiência artística como um todo. Arcar com o peso desse desafio requer compreender os limites que envolvem o mesmo. Não é nossa intenção a de transportar o leitor para dentro da cena, mas gerar nele o mesmo nível de desconforto e de perda das referências que os participantes da cena puderam vivenciar. Não faremos uma construção imagética da cena, mas a sua desconstrução conceitual, assim como ela própria representa a desconstrução da experiência cronológica em função da marcação do instante como momento único de realização do brilho e da morte do vagalume.

Com esse intuito, a primeira questão que devemos nos colocar é sobre a possibilidade de se fazer ainda alguma experiência, sobretudo uma que seja tida como artística. E se ela for possível, então, devemos pensar como desconstruir esse evento para tirar dele o maior proveito possível em termos de uma verdadeira experiência. Feito isso, partiremos para a análise da cena em si.

\section{Da experiência à desconstrução}

A questão da experiência é constantemente revisitada por Walter Benjamin e a marca de sua crítica às limitações da possibilidade de se fazer experiência é um importante ponto de partida para essa análise. No ensaio Experiência, de 1913 (2011, 14-25), Benjamin descreve a acumulação de vivências dos filisteus e a sua transformação na arrogante noção de que é possível tomar posse da experiência como uma atitude a que se deve opor à ação dos jovens. $O$ jovem representa a

\footnotetext{
${ }^{1}$ A aura benjaminiana ou a morte dos vagalumes foi apresentada pelo grupo Ambulatório durante o $1^{\circ}$ Congresso Internacional de Letras, Artes e Cultura (2013) na Universidade Federal de São João del-Rei, como atividade vinculada ao Simpósio Subjetividade e experiência: expressões lúdicas, artísticas e literárias coordenado pelos autores deste artigo. O simpósio foi elaborado como conclusão das atividades do projeto de pesquisa O lúdico e a educação (financiado pela FAPEMIG entre 2010 e 2013).
}

Doutor em Teatro pela Universidade Federal do Estado do Rio de Janeiro-UNIRIO. Professor do curso de graduação em Teatro e do Programa de Pós-Graduação em Artes Cênicas-PPGAC da UFSJ. Brasileiro, residente em São João del Rei MG. Email: quilarduci@ufsj.edu.br 
pureza de uma ação que em sua violência não se limita a instituir ou a manter, mas que aniquila o que está instituído e pretende ser mantido. ${ }^{2}$ A postura de uma violência pura do jovem manifesta-se, assim, como "uma outra experiência" (2011, 24), uma que não se prende à simples acumulação de vivências como os filisteus, não apenas a um ter experiências, porém, como o Zaratustra ao fim de sua jornada, essa força aniquiladora compreende que "sempre se vivencia apenas a si mesmo" $(2011,24)$, e, com essa compreensão, se coloca no exato instante em que se faz a experiência, não para detê-la, mas simplesmente por fazê-la. ${ }^{3}$

O fazer da experiência precisa ser um ato que não esteja associado a uma finalidade específica, senão ele visaria apenas ao acumulo de conteúdos, ao "ter", e não ao "fazer". Para fazer experiência, de fato, é necessário assumir essa ação como "meio puro", uma ação que não esteja direcionada para uma finalidade específica, qualquer que seja ela, mas que se esgota em si mesma; uma ação que, enquanto puro meio, se realiza totalmente em seu acontecer. Nesse sentido, Benjamin, em seu Fragmento teológico-político (2012), trabalha a relação entre a direção profana e a direção messiânica, indicando que ambas produzem o Reino de Deus. Uma vez que as duas direções se encontram quando o Reino é assumido messiânica e profanamente como um termo (Ende), um fim que encerra definitivamente o que está estabelecido, para o qual o messianismo e a profanação do acontecer histórico são meios puros, que realizam o fim (Ende), porque não o

\footnotetext{
${ }^{2}$ A noção de uma violência/poder (Gewalt, é o termo original usado por Benjamin e que sintetiza esse duplo contexto) mítica que institui ou mantém o direito, e que se contrapõe a uma violência/poder pura ou divina que o aniquila, é apresentada no ensaio Sobre a crítica do poder como violência de 1920-1 (2012, 59-82). De acordo com Benjamin a relação entre estas duas possibilidades pode ser descrita em um jogo oposições, "Se o poder mítico é instituinte de um Direito, o divino tende a destruir esse Direito; se aquele impõe limites, este destrói todos os limites; se o poder mítico arrasta consigo, a um tempo, culpa e expiação, o divino absolve; se aquele é ameaçador, este é aniquilador; se um é sangrento, o outro é letal sem ser sangrento" (2012, 79). A experiência do jovem é similar à letalidade sem sangramento da violência divina em sua oposição a qualquer forma instituída de Direito.

3 Essa oposição entre o "ter" e o "fazer" experiência é apresentada por Giorgio Agamben no ensaio Infância e história: ensaio sobre a destruição da experiência $(2008,21-78)$, a partir da análise do personagem Sancho Pança, como aquele que, assim como o filisteu, pode carregar consigo suas experiências e censurar a falta de conhecimento e de senso da realidade dos demais, apesar de ser incapaz de se privar de toda a sua carga e "fazer" de fato qualquer experiência, e de Dom Quixote, como o espírito jovem capaz de "fazer", mas incapaz de "ter" e "deter" as experiências feitas.
}

Doutor em Teatro pela Universidade Federal do Estado do Rio de Janeiro-UNIRIO. Professor do curso de graduação em Teatro e do Programa de Pós-Graduação em Artes Cênicas-PPGAC da UFSJ. Brasileiro, residente em São João del Rei MG. Email: quilarduci@ufsj.edu.br

Doutor em Ciência da Religião pela Universidade Federal de Juiz de Fora. Professor vinculado ao Departamento "Ciências Humanas" da UEMG. Coordenador da pesquisa "Uma política para a formade-vida: Inoperância, messianismo e profanação em Giorgio Agamben" (CNPq). Brasileiro, residente em Barbacena-MG. Email: m-baptista@uol.com.br 
assumem como sua finalidade. Sua função não é chegar ao fim, mas aniquilar o que vem sendo mantido no acontecer histórico. Profanando, ou messianicamente criticando a violência mítica que apenas se preocupa em manter a sacralização de uma ordem caduca, ambas as direções conduzem ao Reino. O que evita o Reino não é a profanação, mas a manutenção do acontecer histórico visando uma meta (Ziel), um fim que só pode ser pensado a partir dos meios utilizados. Um fim (Ziel) para o qual as ações são desenvolvidas, visando assim a manutenção do acontecer histórico, a manutenção do tempo pensado cronologicamente como sequência necessária de fatos. Tanto o messianismo quanto a profanação realizam o Reino enquanto fazem a experiência do tempo cairológico do instante, "fazem" e não "têm" experiência.

A experiência desejada é aquela que consiga romper com a sequência cronológica do tempo e com as sobreposições de fatos históricos e ruínas, ou seja, com todas essas consequências inevitáveis que, segundo a imagem do anjo da história composta por Benjamin na tese IX de Sobre o conceito de história (In: LÖWY, 2005), o progresso impõe. Ação que reconhece o alerta representado pelos olhos esbugalhados do anjo e deixa de frisar sua atenção nas ruínas do passado para salientar o assombro cravado no instante presente. Uma valorização do cairós, o tempo messiânico do instante (jetztzeit) e da decisão soberana, em contraposição à passagem cronológica do tempo.

Essa implicação da vida no momento presente é a única possibilidade de se realizar algo que rompa com a pobreza de experiência que assola nossa realidade e é apresentada por Benjamin em ensaio de 1933 (2008, 114-9). Segundo Benjamin essa pobreza não é algo que seja negada ou combatida pela sociedade; na verdade é assumido como destino daqueles que não aceitaram a proposta do esclarecimento kantiano e preguiçosamente se mantêm na menoridade (KANT, 2005, 61-71). Assumir uma experiência que possa ser rica exige uma postura jovial. Porém, essa jovialidade não pode ser confundida com a menoridade ingênua de se esconder das responsabilidades; precisa ser uma postura a partir da qual se consiga romper com

a falta de aspiração dos menores e produza uma maioridade com espírito jovem Doutor em Teatro pela Universidade Federal do Estado do Rio de Janeiro-UNIRIO. Professor do curso de graduação em Teatro e do Programa de Pós-Graduação em Artes Cênicas-PPGAC da UFSJ. Brasileiro, residente em São João del Rei MG. Email: quilarduci@ufsj.edu.br 
maioridade capaz de se manter em constante atualização capaz de fazer experiência e de viver o tempo presente.

Um arquétipo dessa experiência jovial é, segundo Giorgio Agamben (2008), o cavaleiro Perceval e sua quête pelo Santo Graal. Perceval é aquele "que vê o graal, mas exime-se a ter dele experiência" (AGAMBEN, 2008, 38). O inadvertido cavaleiro de Arthur compromete-se com a busca (quête) do objeto sagrado, mas não transforma essa busca em um objetivo (meta) que deva cumprir apagando todo o sabor do trajeto (hodos). Sua quête não se confunde com um méthodos, cuja estrutura esteja toda organizada cronologicamente tendo em vista a meta final, nela o hodos adquire a função do puro meio cairológico. É por sua jovialidade de não se prender à meta, mas de sentir toda a profundidade do hodos em sua quête que Perceval faz a experiência do Graal sem poder tomá-la para si. Ele encontra o objeto que tanto persegue, algo que nenhum outro cavaleiro conseguiria fazer, ao menos não nos textos originais de Chrétien de Troyes; contudo, não se dá conta de que o encontrou. Ele não poderia assumir toda a força desse encontro sem romper com sua fragilidade humana, sem deixar de lado a sua jovialidade e vestir-se com a objetividade dos filisteus. Porém, se ele se transformasse em um filisteu, então toda a possibilidade de fazer experiência teria se perdido. O único modo de fazer experiência do Graal é eximindo-se de fazer experiência dele, abdicando dos pressupostos que guiam o filisteu em sua busca, entrando no hodos sem uma meta, estando aberto à possibilidade de que essa experiência seja terminal. Uma experiência que só pode acontecer na jovialidade do espírito e que se esvai enquanto o espírito ainda mantém a sua jovialidade.

A experiência de Perceval, enquanto arquétipo da experiência jovial, indica que a maioridade que se deve adquirir para romper com a menoridade não pode ser confundida com o acúmulo de experiências que se pode ter, como acontece aos filisteus. Trata-se de uma maioridade em que o elemento da abertura crítica proposta por Kant supera o do domínio de conhecimentos. Portanto, o sujeito que ao mesmo tempo encontrou sua maioridade e se mantém jovem é aquele que consegue entender o valor do hodos enquanto realização da crítica, ou seja, como o Doutor em Teatro pela Universidade Federal do Estado do Rio de Janeiro-UNIRIO. Professor do curso de graduação em Teatro e do Programa de Pós-Graduação em Artes Cênicas-PPGAC da UFSJ. Brasileiro, residente em São João del Rei MG. Email: quilarduci@ufsj.edu.br 
momento único de realização da experiência, não visando uma construção posterior, mas em toda a sua riqueza momentânea, em toda a riqueza que se encontra no brilho do vagalume em meio à mais completa escuridão. Um brilho que não se pode simplesmente dominar, que não se pode simplesmente conquistar, mas que é possível experimentar usando da capacidade crítica de uma maioridade juvenil. Com sua quête, Perceval pode nos demonstrar que todo Graal a que buscamos é apenas "o impossível ponto de fuga" com o qual temos que lidar em nossa vida, "o que constitui a própria experiência humana como aporia, ou seja, literalmente, como ausência de via" (AGAMBEN, 2008, 38). O caráter aporético da vida denuncia a impossibilidade de uma fuga por meio de uma meta construída intencionalmente e demarca o momento da vivência como único verdadeiramente importante, o momento em que se vive a presença do graal, não como objeto perseguido, mas como objeto ofertado. A via só existe como algo a ser trilhado, não como ponto de fuga. Somente como um hodos, não como uma meta.

A jovialidade da experiência de Perceval é uma representação da experiência que ainda é possível fazer em termos de arte. Se, conforme propõe Agamben (2008), já não se pode mais fazer a experiência comum, posto que o homem moderno é atropelado por uma mixórdia de eventos que o extenua, mas não podem se transformar em algo verdadeiramente duradouro $(2008,22)$, então é necessário pensar essas outras experiências possíveis no lapso de tempo em que os eventos podem ser mais significativos. É necessário agir jovialmente para ser contemporâneo, para estar todo inteiro no tempo presente. Com o objetivo de negar a impossibilidade da experiência, é preciso viver o cairós, o jetztzeit, o agora, como única via de vida. É necessário assumir a jovialidade e a leveza que demarcam a vida a partir de seu caminhar e não de suas metas. Assumir a jovialidade de ser contemporâneo, portanto, não é nada fácil: exige uma contraposição ante toda a luz que se pretende lançar sobre o mundo, tornando-o um objeto completamente revelado. Ou seja, a contemporaneidade exige a negação da experiência dos filisteus como base para construção da realidade; exige uma atitude de buscar a escuridão que está por trás dessa falsa compreensão iluminada do mundo. Buscar, Doutor em Teatro pela Universidade Federal do Estado do Rio de Janeiro-UNIRIO. Professor do curso de graduação em Teatro e do Programa de Pós-Graduação em Artes Cênicas-PPGAC da UFSJ. Brasileiro, residente em São João del Rei MG. Email: quilarduci@ufsj.edu.br 
como Perceval busca o Graal, pelos pontos de luz que não passam de lampejos de vagalumes.

\begin{abstract}
Perceber no escuro do presente essa luz que procura nos alcançar e não pode fazê-lo, isso significa ser contemporâneo. Por isso os contemporâneos são tão raros. E por isso ser contemporâneo é, antes de tudo, uma questão de coragem; porque significa ser capaz não apenas de manter fixo o olhar no escuro da época, mas também de perceber nesse escuro uma luz que, dirigida para nós, distancia-se infinitamente de nós. Ou ainda: ser pontual num compromisso ao qual se pode apenas faltar (AGAMBEN, 2009, 65).
\end{abstract}

A capacidade de ver o escuro de nosso tempo é fundamental para se realizar qualquer experiência. As luzes propagadas pelo pretenso saber têm a função de nos cegar e de destruir a possibilidade de se fazer experiência. A ação que vai na contramão desse cegamento é a de se negar às luzes ofuscantes em função dos lampejos em meio à escuridão, uma ação que exige a coragem de negar e destruir tudo aquilo que foi imposto e falsamente construído para manter a pobreza de experiência de nosso tempo.

A construção de uma cena que se passa em uma sala escura com pequenos flashes de luz que ao mesmo tempo norteiam e desnorteiam os participantes, fazendo parte dessa ânsia por ser contemporâneo, por fazer a experiência que é possível aos jovens. A experiência de uma arte que não se direciona ao espectador, uma arte para artistas. "Se ainda precisamos de uma arte, é para nós convalescentes, outra arte, uma arte zombeteira, leve, fluida, divinamente livre e artificial, tal qual o fluxo da chama clara em meio de céu sem nuvens. E antes de qualquer outra cousa, uma arte para artistas - exclusivamente para artistas" (NIETZSCHE, 1998, 13). A arte exclusivamente para artistas proposta por Nietzsche é a arte a partir da qual se pode fazer experiência e não só acumular aquelas repassadas pelos outros, uma arte da qual é possível ser contemporâneo, que não se limita à simples técnica (téchne), mas que resgata seu sentido de construção (poiésis).

Poiésis, poesia, não designa aqui uma arte entre outras, mas é o nome do fazer mesmo do homem, daquele operar produtivo do qual o fazer artístico é apenas um exemplo eminente e que parece hoje estender, em uma

Doutor em Teatro pela Universidade Federal do Estado do Rio de Janeiro-UNIRIO. Professor do curso de graduação em Teatro e do Programa de Pós-Graduação em Artes Cênicas-PPGAC da UFSJ. Brasileiro, residente em São João del Rei MG. Email: quilarduci@ufsj.edu.br

Doutor em Ciência da Religião pela Universidade Federal de Juiz de Fora. Professor vinculado ao Departamento "Ciências Humanas" da UEMG. Coordenador da pesquisa "Uma política para a formade-vida: Inoperância, messianismo e profanação em Giorgio Agamben" (CNPq). Brasileiro, residente em Barbacena-MG. Email: m-baptista@uol.com.br 
dimensão planetária, a sua potência no fazer da técnica e da produção industrial (AGAMBEN, 2012, 103).

Uma arte que produz e constrói o homem, em que todos estão envolvidos como artistas, que nos lança na escuridão do tempo do agora e permite a nossa experiência, uma arte que precisa ser desconstruída para permitir que vejamos o brilho fugidio dos vagalumes.

\title{
2 A Desconstrução nas Artes Cênicas: uma proposta
}

A investigação teatral, desde as duas últimas décadas do século passado, tem se ocupado cada vez mais em analisar a artesania cênica, os mecanismos e as representações poéticas presentes na cena. $O$ ato de compartilhamento dos processos criativos cênicos possibilita, mesmos com os riscos, trilhar caminhos distintos da representação de um texto já existente.

\begin{abstract}
O que se decide compartilhar ou mostrar não é uma técnica ou regra de como fazer o "trabalho de mesa" para interpretar o texto, ou como dividir os papeis entre os atores e marcar um roteiro cênico. A força destas demonstrações está nos processos de investigação, acumulação e criação dos atores, em diálogo com seus colaboradores e diretores. São esses caminhos de busca, experimentação, resultados, dúvidas, reflexões, onde se integram saberes culturais, aprendizagens espirituais e intelectuais, riscos corporais e confrontações humanas, que o grupo de artistas decide compartilhar de maneira ampla ou restrita. (DIÉGUEZ, 2004, 6)
\end{abstract}

Como afirma Diéguez (2004), é justamente o compartilhar dos processos dos grupos de teatro e dos atores ou atrizes na América Latina que o termo "desmontagem" começou a ser usado. Devido às múltiplas possibilidades de entendimento do termo, existe hoje um frutífero debate filosófico e político sobre essas práticas teatrais. Dessa forma, a desmontagem também começou a influenciar os campos da pedagogia e da licenciatura em teatro, ao colocar em debate os dispositivos, percursos e propostas cênicas, transformando o próprio debate em performances pedagógicas. Essas práticas teatrais começaram, pois, a questionar

Doutor em Teatro pela Universidade Federal do Estado do Rio de Janeiro-UNIRIO. Professor do curso de graduação em Teatro e do Programa de Pós-Graduação em Artes Cênicas-PPGAC da UFSJ. Brasileiro, residente em São João del Rei MG. Email: quilarduci@ufsj.edu.br

Doutor em Ciência da Religião pela Universidade Federal de Juiz de Fora. Professor vinculado ao Departamento "Ciências Humanas" da UEMG. Coordenador da pesquisa "Uma política para a formade-vida: Inoperância, messianismo e profanação em Giorgio Agamben" (CNPq). Brasileiro, residente em Barbacena-MG. Email: m-baptista@uol.com.br 
conceitos como o de representação e de presença cênica que, até então, repousavam confortavelmente dentro de certas disciplinas e saberes, colocando em dúvida a própria ideia de arte, de contemplação e da eficácia poética.

[...] o propósito de desmontar processos teatrais coloca em discussão de valor o sistema estrutural ao submete-lo ao olhar dos outros sem pretender perpetuar modelos, colocando no terreno da discussão a consistência dura das categorias, das poéticas e dos sistemas fechados de valorização e pensamento. Trata-se de processos mais próximos às imersões investigativas, aos acasos e pequenos resultados e de maneira alguma pretendem totalizar a experiência criativa. Em cada um desses processos a investigação tem sido uma experiência particularizada por necessidades práticas, culturais e sociais de cada contexto de representação. (DIÉGUEZ, 2004, 8)

Neste sentido, a partir desse desmontar, busca-se realizar o noção nietzschiana de uma arte para artistas, uma arte capaz de realizar uma experiência jovial.

É a partir desse esforço que o grupo Ambulatório 4 iniciou os seus trabalhos de criação da cena $A$ aura benjaminiana ou a morte dos vagalumes. ${ }^{5}$ De imediato, é possível indicar dois encaminhamentos que já desvelam determinados compromissos assumidos pelo grupo. A cena foi elaborada após a leitura e discussão entre os membros do grupo do texto Sobrevivência dos vaga-lumes

4 O Ambulatório é um grupo de pesquisas e práticas teatrais do curso de Teatro da Universidade Federal de São João del-Rei-UFSJ, coordenado pelo professor Cláudio Guilarduci. O grupo conta com alunos de graduação e pós-graduação, além de voluntários que trabalham em diferentes projetos de Extensão, Pesquisa e Ensino. Em nossas experimentações buscamos aliar teoria e prática de forma concomitante, abordando conceitos como Infância, Brincadeiras e Jogos, Memória, História, Narrativa e Experiência. Os projetos discutem temáticas ou teóricos que tenham relação com Walter Benjamin. Atualmente o Ambulatório trabalha a partir da seguinte ementa: A perda, o luto, não espanta, não nos espanta, pois tudo morre. O luto é fruto da luta, é filho, é filho da puta... Até mesmo a linguagem morre quando apenas comunica aquilo que ela foi capaz de nomear. Mais um instrumento de opressão (mais uma universidade!). O problema é ser lúdico, é saber jogar o jogo jogando. O problema é obter a permissão para dançar e "poetar". Esse é o objetivo do nosso Ambulatório: inventar remédios para a alma. Re-mediar o processo de criação-nomeação do mundo. Jogar jogando o jogo da bolha do mundo com a pele que nos protege. Para maiores informações consultar: <http://ambulatorioufsj.wix.com/ambulatorio>.

${ }^{5}$ Equipe de criação e apresentação da cena: Dramaturgista: Cláudio Guilarduci; Roteirista: Douglas Silva Lauria; Atores: Antônio Marcos da Silva e Douglas Silva Lauria; Atrizes: Janaína Braga Trindade, Érika Camila Pereira dos Santos, Romíria Penha Turcheti Vasconcelos, Ana Karla Tzortzato Almeida e Adrilene Magda da Silva; Técnico de iluminação: Ricardo Pereira Fidelis; Iluminadora: Luciana de Oliveira; Assistente de Produção: Diogo.

Doutor em Teatro pela Universidade Federal do Estado do Rio de Janeiro-UNIRIO. Professor do curso de graduação em Teatro e do Programa de Pós-Graduação em Artes Cênicas-PPGAC da UFSJ. Brasileiro, residente em São João del Rei MG. Email: quilarduci@ufsj.edu.br

Doutor em Ciência da Religião pela Universidade Federal de Juiz de Fora. Professor vinculado ao Departamento "Ciências Humanas" da UEMG. Coordenador da pesquisa "Uma política para a formade-vida: Inoperância, messianismo e profanação em Giorgio Agamben" (CNPq). Brasileiro, residente em Barbacena-MG. Email: m-baptista@uol.com.br 
(2011), de Didi-Huberman. A intermitência da luz, a intermitência da imagem que o vaga-lume oferece permitiu refletirmos sobre a imagem dialética discutida por Walter Benjamin. Para o autor berlinense, a imagem dialética é essencialmente estática, mesmo que esteja em um campo filosófico e que discuta ideias transitórias e irreconciliáveis, conforme salienta Buck-Mors (2002, 254), pois a '“síntese' [dialética] não é um movimento em direção à resolução, mas o ponto em que seus eixos se interconectam". Pensar esse ponto de interconexão faz com que tenhamos que nos colocar como contemporâneos da imagem dialética, essencialmente presos à intermitência do brilho dos vagalumes. Rompendo com o cronológico acontecer histórico em um messiânico e profano instante.

A imagem dialética em Benjamin tem o poder de desmontar ou desconstruir a história. Uma força de aniquilação que rompe com o acontecer histórico. É no encontro dos tempos - o presente, como um flash, e o passado que já foi e ficou no escuro - que a imaginação, esse dispositivo que cria imagens para o pensamento, que o Outrora e o Agora possibilitam a criação de ricas constelações de futuro (DIDIHUBERMAN, 2011, 61). Benjamin afirma, ainda, que a imagem dialética não é um movimento que desenvolve, desenrola e/ou cresce, mas que é uma imagem suspensa, uma ruptura no fio da continuidade, um salto - como o do tigre -, para que possamos vivenciar uma outra temporalidade: a do tempo messiânico. Desmontagem e dialética da suspensão estão entrelaçadas e promovem uma visibilidade que é ao mesmo tempo originária e estrutural. A desmontagem da história está vinculada à montagem de um conhecimento novo e mais complexo do tempo (CANTINHO, 2008). Um conhecimento que não se limita à finalidade (Ziel) do tempo, mas que pode levá-lo a seu fim (Ende).

E para exemplificar as possibilidades desse tempo de encontro entre 0 passado e o presente, Didi-Huberman (2011) recorre novamente a Walter Benjamin para indicar que as imagens têm a função de organizar - montar, desmontar, analisar e contestar - o próprio horizonte.

Doutor em Teatro pela Universidade Federal do Estado do Rio de Janeiro-UNIRIO. Professor do curso de graduação em Teatro e do Programa de Pós-Graduação em Artes Cênicas-PPGAC da UFSJ. Brasileiro, residente em São João del Rei MG. Email: quilarduci@ufsj.edu.br 
Organizar o pessimismo significa... esse espaço de imagens, não é de maneira contemplativa que se possa medi-lo. Esse espaço de imagens (Bildraum) que procuramos... é o mundo de uma atualidade integral e, de todos os lados, aberta (die welt allseitiger und integraler Aktualität)". (DIDIHUBERMAN, 2011, 118) ${ }^{6}$

A pura abertura desse mundo que se apresenta é a única possibilidade de romper com a necessária finalidade das coisas. A abertura permite compreender o meio como fundamento da própria ação, permite a vivência da experiência jovial, que não se limita a uma mera contemplação inativa do acontecer histórico, mas que se torna atuante sobre ele.

O segundo encaminhamento que está na base do Ambulatório é a presença efetiva dos conceitos trabalhados por Walter Benjamin e os caminhos abertos por ele nos mais diferentes campos do saber. Tanto é assim que o presente ensaio dialoga com o texto $O$ Narrador ao considerar as camadas artesanais tanto na construção da cena e nas discussões sobre ela quanto na elaboração do presente texto. Por isso, um dos exercícios realizados com a equipe de alunos que participou da cena foi a criação de um texto individual que fosse capaz de narrar as sensações vividas durante a experimentação cênica e, com isso, experimentar a autoridade que cada um possuía em relação ao processo coletivo de construção da cena. exercício da escrita partiu do pressuposto que a construção (da cena) pressupunha a sua própria desconstrução. Esse exercício favorece que a construção/desconstrução da cena aconteça como uma forma de valorizar o meio e não apenas o produto final (Ziel) a ser apresentado. Narradores de si mesmos, os construtores/desconstrutores da cena fazem a experiência poiética integral para permitir que a cena não se direcione a espectadores, mas seja realmente uma "arte para artistas".

${ }^{6} \mathrm{O}$ texto citado pode ser encontrado no livro $\mathrm{O}$ anjo da história $(2012,180$, Novas teses $\mathrm{K}$ ). $\mathrm{Na}$ realidade, esse fragmento foi extraído do texto Surrealismo (1929). Devido às dificuldades de tradução ver os livros Documentos de cultura, documentos de barbárie: escritos escolhidos (1986, 114) e Magia e técnica, arte e política: ensaios sobre literatura e história da cultura $(1994,34)$.

Doutor em Teatro pela Universidade Federal do Estado do Rio de Janeiro-UNIRIO. Professor do curso de graduação em Teatro e do Programa de Pós-Graduação em Artes Cênicas-PPGAC da UFSJ. Brasileiro, residente em São João del Rei MG. Email: quilarduci@ufsj.edu.br 
A "arte para artistas" está na base da interpretação feita do texto $A$ sobrevivência dos vaga-lumes (2011), no qual o interesse do grupo recaiu especificamente sobre a possibilidade de, a partir de uma cena, ser capaz de experimentar o conceito de "aura" e/ou de "experiência aurática", que foram reformulados várias vezes por Benjamin. Podemos afirmar que esse conceito quer indicar uma categoria da percepção, pois o ato de "observar em repouso" está longe da tradição filosófica de que a contemplação se opõe à ação. Para o historiador alemão, esse contemplar está vinculado a uma ação de grande profundidade entre aquele que observa e aquele que é observado. Rompe-se, assim, com a experiência meramente estética do objeto que se manifesta para a análise do espectador que deve valorizar a poiética construção que acontece nesse contato. A "aparição única de uma coisa distante, por mais perto que ela esteja" é o resultado do nível de presença imediata que pode existir entre sujeito e objeto em determinado lugar e em determinado momento.

A passagem do entendimento conceitual para uma prática estética aponta para uma das indicações benjaminianas apresentada no Konvolut Teoria do Conhecimento, Teoria do Progresso sobre a tarefa do pesquisador (historiador), que é saber o que se quer fazer com um conceito e até onde se quer torná-lo operatório.

Para o dialético, o que importa é ter o vento da história universal [Weltgeschichte] em suas velas. Pensar significa para ele: içar as velas. 0 que é decisivo é como elas são posicionadas. As palavras são suas velas. O modo como são dispostas transforma-as em conceitos. (BENJAMIN, 2006, 515 [N 9, 6])

Dispor as palavras de forma a romper com a manutenção dos acontecimentos históricos e favorecer a irrupção do tempo cairológico é a única forma de fazer experiência. A experiência não foi totalmente abolida, mas aprisionada por dispositivos que tendem a indicar onde as palavras devem ser colocadas. A violência mítica das gramáticas impede a violência aniquiladora e dialética de dispor as palavras em conceitos verdadeiramente poéticos. A experiência que nos cabe curso de graduação em Teatro e do Programa de Pós-Graduação em Artes Cênicas-PPGAC da UFSJ. Brasileiro, residente em São João del Rei MG. Email: quilarduci@ufsj.edu.br 
ainda deve ser guiada por imagens de pensamento que permitam uma disposição diferente das palavras.

Duas Imagens do Pensamento presentes no livro Rua de Mão Única (1995) são importantes para o processo de desconstrução da cena. O primeiro é o Escavando e recordando (1995, 239-240). Esse texto possibilita uma reflexão sobre a relação existente entre a memória e o tempo pretérito. Para aproximar do passado soterrado, é necessário revolver e espalhar os "fatos", semelhantemente ao trabalho de escavações de solo. No entanto, inventariar as preciosidades encontradas não é suficiente para o entendimento desse passado, pois a memória é apenas o meio para encontrar o tempo de outrora. As "verdadeiras lembranças" necessitam tanto do inventário quanto do rigor da indicação do lugar onde foi encontrada cada relíquia: é no cruzamento da listagem daquilo que foi encontrado com a exatidão de onde e como o "investigador" se apoderou dos achados que o túmulo, sèma, poderá ser aberto.

No fragmento M 16a, 4, presente na obra Passagens (2006, 490), Benjamin, ao estabelecer uma relação entre a aura e o rastro, indica o paradoxo existente entre o perto e o longe: "Rastro e aura. O rastro é a aparição de uma proximidade, por mais longínquo esteja aquilo que o deixou. A aura é a aparição de algo longínquo, por mais próximo esteja aquilo que a evoca. No rastro, apoderamo-nos da coisa; na aura, ela se apodera de nós". Os elementos auráticos da experiência estética em Benjamim são um processo perceptivo que só ocorre em determinadas condições temporais e especiais, mas que não se resume à experiência de uma única percepção visual, pois esse instante, o aurático, se comunica com a pessoa como um todo. Esse aurático apoderar-se realiza a disposição das palavras em conceitos que não se limitam à reprodução do acontecer histórico, abrindo para a experiência jovial que nos constrói e nos desconstrói ao mesmo tempo.

A essa Imagem do Pensamento é possível associar uma das siglas criadas por Benjamin durante o processo de escrita do livro Passagens (2006). O autor criou uma escrita secreta com 30 siglas em cores, mas somente uma foi elaborada utilizando duas figuras de duas dimensões: um círculo preto dentro de um quadrado Doutor em Teatro pela Universidade Federal do Estado do Rio de Janeiro-UNIRIO. Professor do curso de graduação em Teatro e do Programa de Pós-Graduação em Artes Cênicas-PPGAC da UFSJ. Brasileiro, residente em São João del Rei MG. Email: quilarduci@ufsi.edu.br 
amarelo. As demais figuras dessa escrita são formadas por ponto, linha e plano. Paris Ctônica é formada por duas figuras fazendo com que o leitor seja capaz de visualizar um cone. Possivelmente, Walter Benjamin, no momento da criação dessa figura, faz referência à figura do cone invertido de Bergson, apresentada no texto Matière et mémoire. Tanto é assim que Benjamin, no texto sobre Baudelaire, afirma que

\begin{abstract}
Pode-se considerar a obra de Proust, Em Busca do Tempo Perdido, como a tentativa de reproduzir artificialmente, sob as condições sociais atuais, a experiência tal como Bergson a imagina, pois cada vez se poderá ter menos esperanças de realizá-la por meios naturais. Proust, aliás, não se furta ao debate desta questão em sua obra, introduzindo mesmo um elemento novo, que encerra uma crítica imanente a Bergson. [...] Já de início Proust identifica terminologicamente a sua opinião divergente. A memória pura $-a$ mémoire pure - da teoria bergsoniana se transforma, em Proust, na mémoire involontaire. (Benjamin, 1994, 105-106)
\end{abstract}

Com a Paris Ctônica, Benjamin nos lança na esfera da memória pura ou involuntária que auraticamente realiza a disposição das palavras em um conceito diverso daquele mantido pela violência mítica.

A segunda Imagem do Pensamento que auxilia no entendimento da desconstrução da cena é $O$ caráter destrutivo (1995, 235-237). Nesse fragmento está presente a ideia de combate a tudo aquilo que está estabilizado, intocado e conservado como verdadeiro para abrir caminhos, novas possibilidades que se cruzam. Portanto, não é uma rua de direção única ou a construção de um único caminho. O caráter destrutivo valoriza o potencial das coisas e assegura o pensamento dialético, por isso o adversário do caráter destrutivo é o homem-estojo, o burguês que vive aprisionado em sua moradia-estojo com a promessa de felicidade. Esse interior que cria a imagem de aconchego, conforto e segurança é o mesmo que é resultado de um raciocínio tecnocrático que busca acondicionar com perfeição seus moradores causando uma privação da vida pública. O burguês, para Benjamin, aspira fazer da sua morada um museu que reúne, no conforto da sua casa, uma coleção para que ele possa contemplar o mundo a uma distância

Doutor em Teatro pela Universidade Federal do Estado do Rio de Janeiro-UNIRIO. Professor do curso de graduação em Teatro e do Programa de Pós-Graduação em Artes Cênicas-PPGAC da UFSJ. Brasileiro, residente em São João del Rei MG. Email: quilarduci@ufsj.edu.br

Doutor em Ciência da Religião pela Universidade Federal de Juiz de Fora. Professor vinculado ao Departamento "Ciências Humanas" da UEMG. Coordenador da pesquisa "Uma política para a formade-vida: Inoperância, messianismo e profanação em Giorgio Agamben" (CNPq). Brasileiro, residente em Barbacena-MG. Email: m-baptista@uol.com.br 
confortável. A acumulação de bens é a representação desse homem-estojo, um colecionador que se torna uma espécie de "flâneur congelado". (BOLLE, 2000, 379)

\begin{abstract}
O caráter destrutivo conhece apenas uma divisa: criar espaço; conhece apenas uma atividade: abrir caminho, Sua necessidade de ar puro e de espaço é mais forte do que qualquer ódio. $O$ caráter destrutivo é jovem e sereno. Pois destruir rejuvenesce, porque afasta as marcas da nossa própria idade; reanima, pois toda eliminação significa, para o destruidor, uma completa redução, a extração da raiz de sua própria condição. O que leva a esta imagem apolínea do destruídos é, antes de mais nada, o reconhecimento de que o mundo se simplifica terrivelmente quando se testa o quanto ele merece ser destruído. [...] O caráter destrutivo não tem o mínimo interesse em ser compreendido. Considera superficiais quaisquer esforços nesse sentido. (BENJAMIN, 1986, 187).
\end{abstract}

O caráter destrutivo é a marca da jovialidade da experiência que não se propõe a realizar a instituição de algo novo ou a manutenção do velho, apenas aniquila o acontecer histórico e permite que, no vazio criado, se possa fazer uma aurática experiência de si mesmo.

\title{
3 A experimentação cênica ${ }^{7}$
}

A cena apresentada, enquanto realização artística da experiência de aniquilação, foi apresentada a um público convidado, basicamente restrito às pessoas que participavam do Simpósio Subjetividade e experiência. Nesse sentido, os participantes estavam imersos na discussão conceitual de um lúdico com características profanadoras do acontecer histórico quando foram conduzidos para a concretização da experiência conceitual. Enquanto aguardavam do lado de fora da Sala Preta - local onde iria acontecer a experimentação - , eles sabiam que a experiência a ser proposta não seria uma convencional apresentação teatral, mas não conseguiam formular o que seria concretizado. O primeiro contato surge com

\footnotetext{
7 A descrição da cena é feita a partir de relatos dos atores envolvidos. Uma primeira versão deste texto foi publicada em: GUILARDUCI, Cláudio; BAPTISTA, Mauro Rocha. O que resta da experiência: Um ensaio sobre duas cenas do grupo Ambulatório-UFSJ. Plural Pluriel, [S.I.], n. 14, oct. 2016. ISSN 1760-5504. Disponível em: <http://www.pluralpluriel.org/index.php/revue/article/view/32>. Acesso em: 17 sep. 2017. A atual versão foi complementada pelas análises conceituais do presente artigo.

Doutor em Teatro pela Universidade Federal do Estado do Rio de Janeiro-UNIRIO. Professor do curso de graduação em Teatro e do Programa de Pós-Graduação em Artes Cênicas-PPGAC da UFSJ. Brasileiro, residente em São João del Rei MG. Email: quilarduci@ufsj.edu.br
}

Doutor em Ciência da Religião pela Universidade Federal de Juiz de Fora. Professor vinculado ao Departamento "Ciências Humanas" da UEMG. Coordenador da pesquisa "Uma política para a formade-vida: Inoperância, messianismo e profanação em Giorgio Agamben" (CNPq). Brasileiro, residente em Barbacena-MG. Email: m-baptista@uol.com.br 
uma mão por entre um tecido negro que os convida a entrar. Toda a sala está no escuro e a plateia é conduzida por dentro de um tecido preto. ${ }^{8}$ A escuridão retira qualquer segurança possível. Não existe a possibilidade de se guiar por rastros. A plateia nada vê nesse espaço desconhecido e, ao mesmo tempo, é conduzida pelo tecido preto que os atores seguram. Deixando-se conduzir, até porque não existe outra possibilidade, a plateia chega ao espaço em que a cena se desenvolverá. Nesse momento, o som de instrumentos - flauta de bambu, caxixi, apito e atabaque - auxiliam na construção da ambiência. Assim, o jogo na caixa do inconsciente se instaura.

Os espaços criados com o uso de um tecido que conduz a plateia dentro da sala foi elaborado a partir das figuras geométricas pensadas por Benjamin para criar sua escrita secreta. O primeiro espaço para a plateia se movimentar é um retângulo. A única possibilidade para a plateia ver alguma coisa na sala é dado por uma chama de uma lamparina. Os atores circundam brincando, jogando e tocando as pessoas que estão dentro do espaço formado pelo tecido. A lamparina acesa torna-se um ponto de fuga na escuridão, mas a segurança desse ponto de fuga é constantemente retirada pelo movimento dos atores que surgem de espaços diferenciados. Aos poucos, os participantes são levados a não buscar mais a lamparina e a se deixar guiar pelos toques que surgem em meio aos tecidos. Tal qual na experiência jovial, as seguranças vão sendo trocadas pela vivência do caminho. Ao apagar da lamparina, um foco azul se acende no centro do tecido e a plateia se vê como parte da cena. Nesse momento, todos se olham e compreendem que não fazem parte de um grupo de espectadores. Na experiência aurática não cabe uma arte que não seja para artistas. Ao se perceberem como integrantes da cena, alguns se recolocam no espaço com movimentos suaves e silenciosos

Nesse momento, é dado o primeiro estímulo: um grande balão preto, que contém algo não identificado em seu interior, é jogado dentro do quadrado. A plateia

\footnotetext{
${ }^{8} \mathrm{~A}$ primeira parte da descrição da cena foi elaborada a partir do relato elaborado pela atriz Ana Karla Tzortzato.
}

Doutor em Teatro pela Universidade Federal do Estado do Rio de Janeiro-UNIRIO. Professor do curso de graduação em Teatro e do Programa de Pós-Graduação em Artes Cênicas-PPGAC da UFSJ. Brasileiro, residente em São João del Rei MG. Email: quilarduci@ufsj.edu.br 
brinca com o balão enquanto ouve o barulho de outros balões sendo estourados do lado de fora. Quando o grande balão estoura, os participantes da cena recebem, de dentro, do balão determinados estímulos. Alguns executam as ações sugeridas, outros simplesmente as ignoram. O fundamental não é obrigar que os participantes instituam uma nova ordem a partir dos estímulos ofertados, mas que saiam da antiga segurança. Os estímulos não precisam ser assumidos como ordens, mas trazem os participantes para o centro do palco, ignorando ou não o que foi ofertado. Sabendo que são parte da cena, eles ganham uma nova segurança, até mesmo para negar a sua participação. Nesse instante de nova confiança adquirida, o azul da cena vai aos poucos se apagando até que a escuridão retorna e o desconhecido é novamente instaurado. As recém-adquiridas novas seguranças são retiradas novamente; se a experiência jovial perdura ela se perde de sua jovialidade.

Nesse momento, o quadrado formado pelo tecido ganha uma nova divisão, formando dois triângulos. Exprimidos em duas extremidades, os participantes apenas sentem e ouvem, pois a escuridão não permite que eles possam enxergar o que está ocorrendo ao seu redor. Em alguns momentos, luzes de lanternas piscam, dando uma orientação de direção no espaço. As luzes piscam semelhantemente aos vaga-lumes durante seus jogos de acasalamento. Como não existe um padrão para o piscar das lanternas, não existe uma possibilidade de construir algo a partir delas. Os participantes estão abertos a uma experiência que auraticamente toma posse deles. Aos poucos cada um vai abdicando de compor uma realidade e se deixa levar por uma construção poiética coletiva.

É iniciado o terceiro estímulo, o contato-improvisação: mãos e corpos se tocam improvisadamente, tocam o tecido e sentem os atores que os tocam a partir do outro lado do tecido. Esse é o primeiro passo para formação do labirinto. A divisória se recolhe, a plateia é conduzida para a formação da espiral, que os leva para o labirinto (esse talvez seja a peça basilar da cena). ${ }^{9} \mathrm{O}$ labirinto é pensado não na concretude da cena, mas na perda das referências espaciais e temporais que a

${ }^{9}$ Relato do Ator Douglas Silva Lauria.

Doutor em Teatro pela Universidade Federal do Estado do Rio de Janeiro-UNIRIO. Professor do curso de graduação em Teatro e do Programa de Pós-Graduação em Artes Cênicas-PPGAC da UFSJ. Brasileiro, residente em São João del Rei MG. Email: quilarduci@ufsj.edu.br 
cena provoca: a sensação, o incômodo do imprevisível, a suspensão da cena espetacular. A partir do momento que os participantes assumem seu desconforto com o piscar das lanternas, ao passo que até mesmo esse desconforto lhes é retirado pela produção de um labirinto. A cena conduz constantemente à substituição de seguranças adquiridas. Nada pode ser assumido como duradouro. As seguranças constituídas cronologicamente pelo acontecer histórico são substituídas vez após outra, até culminar em um sugestivo labirinto. Sem o novelo de Ariadne para guiar os participantes, a compreensão é de que o caminho não existe previamente. O labirinto vai se construindo à medida em que vai sendo caminhado. Não se trata de uma sequência cronológica de fatos que conduzem à inevitável exposição de um sentido; são fragmentos cairológicos que se acumulam uns após os outros e se perdem instantaneamente logo a seguir.

O labirinto conduz os participantes para um novo espaço: todos ficam em um canto da sala, posicionados dentro de um triângulo formado no espaço. Nesse momento, um baú negro desce à frente do triângulo. Os atores começam a explorálo, mostrando os objetos que estavam dentro. Os atores começam a brincar com os objetos: elástico, bolhas de sabão, fita e bolas de neon. A beleza e leveza dos gestos conduzem a uma nova sensação de tranquilidade. As brincadeiras remetem cada um às suas próprias memórias de infância. Aos poucos uma nova sensação de conforto vai se estabelecendo.

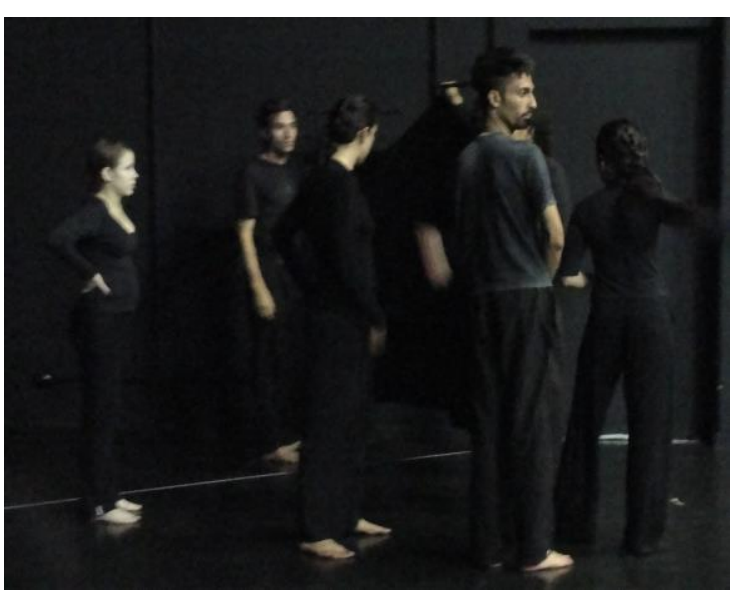

Atores durante o ensaio da cena

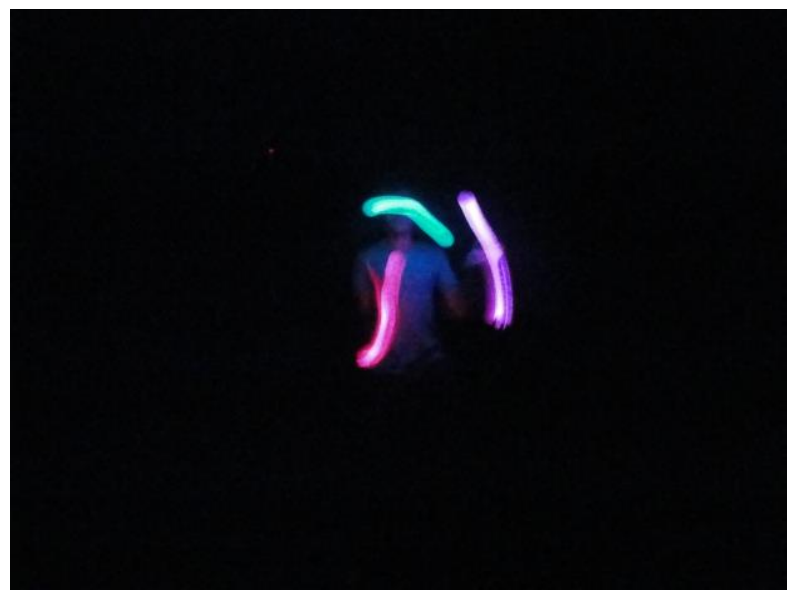

Ator Douglas Lauria jogando bolas de neon

Doutor em Teatro pela Universidade Federal do Estado do Rio de Janeiro-UNIRIO. Professor do curso de graduação em Teatro e do Programa de Pós-Graduação em Artes Cênicas-PPGAC da UFSJ. Brasileiro, residente em São João del Rei MG. Email: quilarduci@ufsj.edu.br

Doutor em Ciência da Religião pela Universidade Federal de Juiz de Fora. Professor vinculado ao Departamento "Ciências Humanas" da UEMG. Coordenador da pesquisa "Uma política para a formade-vida: Inoperância, messianismo e profanação em Giorgio Agamben" (CNPq). Brasileiro, residente em Barbacena-MG. Email: m-baptista@uol.com.br 
Foto: Janaína Braga Trindade Acervo do Ambulatório

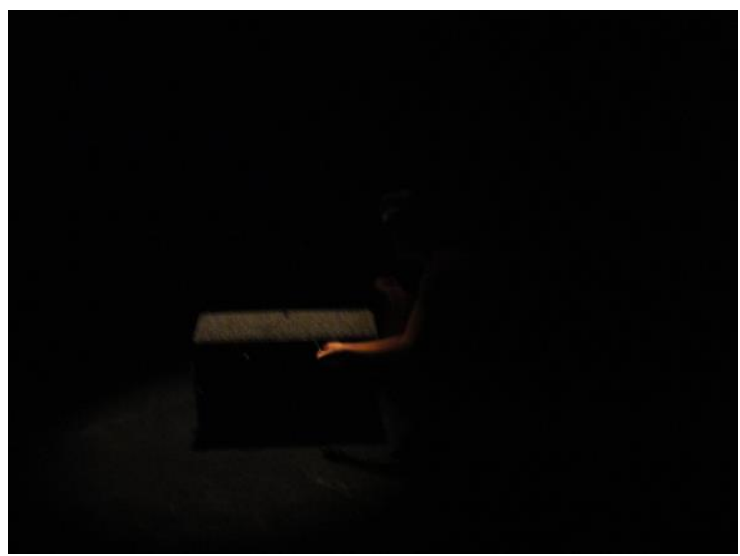

Baú de brinquedos

Foto: Janaína Braga Trindade

Acervo do Ambulatório
Foto: Érika Camila dos Santos

Acervo do Ambulatório

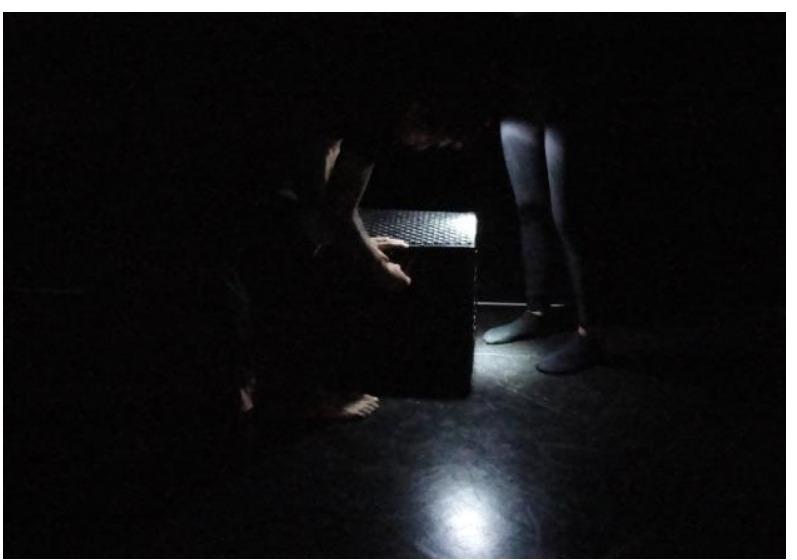

Baú de brinquedos II

Foto: Janaína Braga Trindade

Acervo do Ambulatório

O conforto é quebrado quando, ao fundo, um trecho do poema escrito por Scholem ao amigo Walter Benjamin é lido, e na vitrola toca uma música para embalar esse momento aurático da experiência. O primeiro olhar sobre as coisas, o olhar da criança, o olhar do viajante.

\footnotetext{
Pendo digno da parede / sem olhar a ninguém / Enviado fui do céu / E cá estou anjo-homem.

O humano em mim é bom / mas não me interessa / Sirvo ao bem supremo/ e de rosto não preciso.

O mundo de onde venho / é mensurado, profundo e claro. / E o princípio que me sustenta / aparece aqui em seu resplendor.

Em meu coração a cidade / à qual Deus me enviou / $\mathrm{O}$ anjo com este signo / não sucumbe aos seus encantos.

Asa preste a voar / voltaria de bom grado / pois ao ficar uma vida inteira/ muito feliz não seria.

Meu olho é negro e pleno / meu olhar nunca se esvazia / sei o que tenho, de anunciar / e sei muitas coisas mais.

Não sou símbolo / significo o que sou / Você gira em vão o anel mágico / eu não tenho sentido. (BENJAMIN; SCHOLEM, 1993, 119)
}

Quebradas mais uma vez as seguranças ilusoriamente criadas, ecoa a sentença final do poema: "eu não tenho sentido". Os sentidos são retirados para que se possa significar o que se é, experimentar completamente a ausência de um sentido final, ser meio puro.

Doutor em Teatro pela Universidade Federal do Estado do Rio de Janeiro-UNIRIO. Professor do curso de graduação em Teatro e do Programa de Pós-Graduação em Artes Cênicas-PPGAC da UFSJ. Brasileiro, residente em São João del Rei MG. Email: quilarduci@ufsj.edu.br

Doutor em Ciência da Religião pela Universidade Federal de Juiz de Fora. Professor vinculado ao Departamento "Ciências Humanas" da UEMG. Coordenador da pesquisa "Uma política para a formade-vida: Inoperância, messianismo e profanação em Giorgio Agamben" (CNPq). Brasileiro, residente em Barbacena-MG. Email: m-baptista@uol.com.br 
A sensação labiríntica é relatada por todos os atores a partir da sensação obtida ao adentrar num espaço escuro com apenas alguns relampejos de luz (que ainda se modificam com o bailar do tecido), fazendo com que seja perdida a referência espacial e temporal. ${ }^{10}$ Além da ausência das referências de tempo e de espaço, os atores também relataram a sensação do momento da experimentação que não exigia nem interpretação e nem representação. A cena foi ensaiada apenas com a combinação de ações e sempre partiu da suposição de determinadas reações do público. O que realmente iria acontecer durante a experimentação cênica era um mistério. A sensação labiríntica também tomou os próprios atores. Além disso, o momento da leitura do poema foi relatado como o instante de maior intensidade do jogo ${ }^{11}$, sendo que este nos conduz a todos, artistas ou participantes, para um mesmo sentido de arte, uma arte para artistas. Uma arte para a jovial experiência.

\section{REFERÊNCIAS}

AGAMBEN, Giorgio. O homem sem conteúdo. Belo Horizonte: Autêntica, 2012.

AGAMBEN, Giorgio. Infância e história: Destruição da experiência e origem da história. Belo Horizonte: Editora UFMG, 2008.

AGAMBEN, Giorgio. O que é o contemporâneo? E outros ensaios. Chapecó: Argos, 2009.

BENJAMIN, Walter. Magia e técnica, arte e política: ensaios sobre literatura e história da cultura. 7.ed. São Paulo: Brasiliense, 2008.

BENJAMIN, Walter. O anjo da história. Belo Horizonte: Autêntica, 2012.

BENJAMIN, Walter. Passagens. Belo Horizonte: Editora UFMG; São Paulo: Imprensa Oficial do Estado de São Paulo, 2006.

\footnotetext{
${ }^{10}$ Relato da atriz Romíria Turchetti

${ }^{11}$ Relato da atriz Janaína Braga Trindade.
}

Doutor em Teatro pela Universidade Federal do Estado do Rio de Janeiro-UNIRIO. Professor do curso de graduação em Teatro e do Programa de Pós-Graduação em Artes Cênicas-PPGAC da UFSJ. Brasileiro, residente em São João del Rei MG. Email: quilarduci@ufsj.edu.br 
BENJAMIN, Walter. Reflexões sobre a criança, o brinquedo e a educação. 2.ed. São Paulo: Duas cidades; Editora 34, 2011.

BENJAMIN, Walter. Documentos de cultura, documentos de barbárie: escritos escolhidos. São Paulo: Cultrix: Editora da Universidade de São Paulo, 1986.

BOLLE, Willi. Fisiognomia da Metrópole Moderna: representação da História em Walter Benjamin. São Paulo: Editora da Universidade de São Paulo, 2000.

BUCK-MORS, Susan. Dialética do olhar: Walter Benjamin e o Projeto das Passagens. Belo Horizonte: Editora da UFMG; Chapecó: Editora Universitária Argos, 2002.

CANTINHO, Maria João. O voo suspenso do tempo: estudo sobre o conceito de imagem dialéctica na obra de Walter Benjamin. Espéculo. Revista de Estudos $\begin{array}{lllll}\text { Literários, } & \text { n. } 39, \quad \text { a. } & \text { XIII, Jul./Out., } & 2008 .\end{array}$ <http://pendientedemigracion.ucm.es/info/especulo/numero39/imadiale.html> Acesso em 13 Set. 2014

DIDI-HUBERMAN, Georges. Sobrevivência dos vaga-lumes. Belo Horizonte: Editora da UFMG, 2011.

DIÉGUEZ, Ileana. Desmontagem cênica. Trad. José Raphael Brito dos Santos; Gilberto dos Santos Martins. Rascunhos, Uberlândia, v. 1 n. 1, p. 5-12 jan./jun. 2014.

GUILARDUCI, Cláudio; BAPTISTA, Mauro Rocha. O que resta da experiência: Um ensaio sobre duas cenas do grupo Ambulatório-UFSJ. Plural Pluriel, [S.I.], n. 14, oct. 2016. ISSN 1760-5504. Disponível em: <http://www.pluralpluriel.org/index.php/revue/article/view/32>. Acesso em: 17 sep. 2017.

LÖWY, Michael. Walter Benjamin: aviso de incêndio: Uma leitura das teses "Sobre o conceito de história". São Paulo: Boitempo, 2005.

KANT, Immanuel. Textos seletos. 3.ed. Petrópolis: Vozes, 2005. Resposta à pergunta: Que é "Esclarecimento"? (Aufklärung), p. 61-71.

NIETZSCHE, Friedrich Whilhelm. A Gaia Ciência. Rio de Janeiro: Ediouro, 1998. Prefácio da segunda edição, p. 9-13.

Doutor em Teatro pela Universidade Federal do Estado do Rio de Janeiro-UNIRIO. Professor do curso de graduação em Teatro e do Programa de Pós-Graduação em Artes Cênicas-PPGAC da UFSJ. Brasileiro, residente em São João del Rei MG. Email: quilarduci@ufsj.edu.br 